\title{
Ethnic Model of Consumer Practices Tatars and Russians of Republic of Tatarstan in the Period of Globalization
}

\author{
Sergey Y. Rychkov ${ }^{1}$, Nadezhda V. Rychkova ${ }^{2}$ \& Gyzel R. Stolyarova ${ }^{3}$ \\ ${ }^{1}$ Institute of Economics, Management and Law, Kazan, Russia \\ ${ }^{2}$ Kazan National Research Technological University, Kazan, Russia \\ ${ }^{3}$ Kazan (Volga region) Federal University, Kazan, Russia \\ Correspondence: Sergey Y. Rychkov, Institute of Economics, Management and Law, Moskovskaya Street 42, \\ Kazan, 420111, Russia. E-mail: lera@rambler.ru
}

Received: January 17, 2015 Accepted: January 29, 2015 Online Published: February 26, 2015

doi:10.5539/res.v7n3p298 URL: http://dx.doi.org/10.5539/res.v7n3p298

\begin{abstract}
The purpose of this article is the comparative analysis of models of consumer practices of Tatars and Russians of the multiethnic region (Republic of Tatarstan, Russia) in the situation of globalization of consumer culture. The problem of modeling consumer practices of ethnic groups considered in the concept of economic anthropology (ethnology). It is concluded that a combination of two opposing processes within consumer practices of ethnic groups in the context of globalization: the erosion of ethno-cultural space and the revival of ethnic and cultural traditions. Value profiles of consumers working age of two ethnic groups of Tatarstan-Tatars and Russians, using the technique of LOV (List of Values), are constructed. Also value profiles further investigated by gender. Constructed value profiles of Tatars and Russians is one of the elements of the model of consumer practices of these ethnic groups. Consumer practices are constantly under the influence of external and internal factors, and their systematic study is the task of further work. Regular monitoring of the dynamics of the consumer practices of ethnic groups allows to monitor the socio-cultural and socio-economic processes in the interests of both the market subjects as well as various social groups.
\end{abstract}

Keywords: consumer practices, ethnic models, value profiles, Tatars, Russians

\section{Introduction}

Consumer behavior is included in the subject field of economic anthropology (ethnology) as part of a behavioral system, as a kind of economic behavior of the representatives of a particular ethnic group. Actualization of scientific needs in the economic and anthropological research discourse associated with changes in economic realities, with the evolution of ideas about the role of the consumer in the economic system of society (Lind de Montoya, 2009; Appadurai, 1986).

Globalization has affected almost every aspect of Tatarstan society's life. The global economy has an impact on the traditional practice of ethnoses. Also opposing flow processes associated with adaptation of global forms to the socio-economic and ethno-cultural characteristics of the region are presented in a society (Cultural values, 2011). Results of the analysis of the local context of globalization of consumer culture indicates a growing interest to ethnic culture in Tatarstan, the revival of traditional cultural forms and practices. On the other hand, there are a blurring of cultural space, new forms of global consumer practices. Russia's WTO (World Trade Organization) membership has increased processes such as globalization and localization.

The purpose of this article is the comparative analysis of models of consumer practices of Tatars and Russians of the multiethnic region (Republic of Tatarstan, Russia) in the situation of globalization of consumer culture. Objectives: 1) To determine the definition of "ethnic model of consumer practices" in the context of modeling the behavior of consumers; 2) To construct the value profiles of consumers-Tatars and Russians; 3) To make a comparative description of profiles obtained using the gender discourse; 4) To compare the ethnic profiles at one of it's elements-focuses of consumer behavior. 


\section{Methods}

\subsection{The Concept of Consumer Behavior}

One of the approaches to the delimitation of the research field of economic anthropology is "ethnicity in the economic field". Under this approach, thematic block "ethnic characteristics of consumer preferences" is allocated. Another approach can be formulated as follows: "The economic actions on the ethnic field". Economic action is considered an act focused on getting subjectively evaluated the benefits, the result of which can be represented as real or perceived advantages. These approaches complement each other and give a synergistic effect.

Consumer behavior has a multidimensional character, its definitions and analysis adequately represented in the scientific literature. The consumer practice, according our understanding, is a combination of methods and ways of organizing space life of household or individual within a specific ethno-cultural environment.

Ethno-cultural environment in the concept of economic anthropology can be represented in the products of material and mental life, in the system of social norms, in spiritual values. Elements of ethno-cultural environment form the concrete consumer's lifestyle and contribute to an understanding of any needs in a particular situation. If need be considered as a sense of incongruity between the desired and the actual state of individual, the desired state, which seeks to achieve a consumer can have individual settings of specific ethno-cultural environment. Products/goods are instruments to achieve the desired state, and consumer requirements for the product, the degree of satisfaction with their orientation of consumer behavior may have ethnic overtones to a certain extent.

\subsection{Modeling Consumer Practices}

One of the methods of scientific knowledge of complex social and economic institutions and processes is a modeling. Modeling of consumer behavior is a logical construction of people's actions in the market environment, to meet the needs. The model is a simplified representation of reality, with the inclusion of aspects important for the creator of the model. The main function of the model - explanatory, as it consists of processes, phenomena which are in a causal relationship. When modeling the consumer behavior, only those aspects of human behavior included in the analysis that are relevant to the behavior on the market (Ilyin, 2000). Thus, the market behavior of individual as a consumer of certain goods and services is modeled. Significant contribution to the study of models of consumer behavior and their classification made Maslow (1943), Blekuell, Miniard and Engel (2005), Kotler (1999), Assael (1993), Lambin (2007), Aleshina (2006), Naumov (2009), Rostovzeva (2002), etc. The conceptual basis for many studies, including in Russia, was the theory of the basic values of Schwartz (2009). For example, a russified version of methodology for assessing value systems used Lebedeva, Tatarko and Pavlenko (Cultural values, 2011), Butenko, Sedova, Lipatova and Shvarts (2012), Gabdrakhmanova (2010) and others.

Ethnic model of consumer practices - representation of consumers ethnically self-determined in the specific economic, legal, political, social, ethnic and cultural, demographic conditions. In conceptual and methodological framework of the economic and anthropological study we can identify the following structural elements of the ethnic model of consumer practices of the final consumers: consumer potential, resources, budget, expenses, income, consumption, gender, age, marital status, values, religious affiliation, decision-making process of buying and the factors that determine it, the response to the actions of market subjects, etc. (Rychkova \& Rychkov, 2013).

In this article we restrict ourselves to a comparative analysis of some elements of the model, influencing the formation of a purchasing decision. To construct the profile of the valuable consumers used the method LOV. The basis of this method is the list of values ( 9 positions), developed L. Kahle and other scientists of questioning Center at Michigan University on the base of the Rokeach's registry values (Rokeach, 1973; Kahle, 1983). Nowadays are known to 418 names of values (List of Values). Method is implemented in the following ways: respondents are asked to identify their two most important values, or arrange them in order of importance, or assessed by comparing pairs, or to quantify. Method's approbations showed its high efficiency with demographic variables.

In addition, the method allows to differentiate consumers in three dimensions: a predominance of internal, external and interpersonal focuses. The method has been widely used in marketing activities, as it based on a system of latent values allows the identification of market segments, that is, to form groups of consumers with similar characteristics. These groups are equally responsive to the incentives of marketing and create favorable marketing opportunities for market's players. 
Database of the research: scientific publications on psychology, economic anthropology, marketing; the official statistics (the results of the National Population Census 2010); the results of original mass interrogations for 2010-2013, conducted by survey method at strata and quota system. Volume of sample was 500 people. Significant signs of stratification were: ethnicity, age. Profile of strata: Russians / Tatars working age of mono / ethnic families residing in the city. Within strata defined by age and gender profile of respondents characteristics. Stratum-students of Kazan's universities - has been allocated. Interest to them had determined by the fact that their economic thinking and consumer behavior formed in the period of market economy in 1990th-2000th.

\section{Results}

\subsection{Characteristics of the Research Object}

The Republic of Tatarstan - a national republic, one of the subjects of the Russian Federation, located in the Volga Federal District, at the confluence of the Volga and Kama rivers. Population-3786488 people, of which $53.2 \%$ are Tatars, $39.7 \%$ - Russians, $3.1 \%$ - Chuvashs, $0.6 \%$ - Udmurts, $0.5 \%$-Mordvinians, $0.5 \%$ - Maris and $0.5 \%$ - Ukrainians. The Republic of Tatarstan is a multiethnic region with well-developed marketing space. Kazan is the capital of Tatarstan. It's population-1176187 people. Ethnic landscape of Kazan is composed of more than 170 ethnic groups, including Tatars-47.55\%, Russians- $48.63 \%$, Chuvashs- $0.78 \%$, Ukrainians - $0.48 \%$, Maris - $0.32 \%$ (Ethnic composition, 2010).

Nowadays market offered the products satisfying almost any need. Ph. Kotler and F. Trias de Bes in their book dedicated to the issues of lateral marketing, predicted that in the twenty-first century to win and retain their consumer companies will be a little more complicated for several reasons (Kotler \& Trias de Bes, 2003). These reasons predictable by classics of marketing can be easily found in the analysis of consumer markets in the city of Kazan.

The first reason is: in the field of standardized consumer goods distribution channels are concentrated in the hands of a few distributors, as a result — increasing their power and influence on the producers and consumers; retailers are moving away from brand management and transferred to the management of product categories.

The second reason is: the need to adapt products to the specific requirements of target segments contributed to the steady growth of the number of brands that allow you to effectively negotiate with distributors, difficult to attack competitors, increased barriers to entry for new competitors and, ultimately, led to a reduction in the number of competitors.

The third reason: for the consumer market the situation of "arms race" is characterized, the peculiar acceleration of the dynamics of production of new brands, the relatively low cost of new brands, a high degree of willingness of consumers to switch to a new brand, reducing product life cycle.

The fourth reason: using and recognition of durable goods as a "one-off" becomes the norm of consumer culture. Increasingly, there is a situation when the replacement of the goods to the consumer is less costly repair.

The fifth reason: the new digital technologies accelerate the pace of innovation, facilitate the emergence of new products and brands. There is a significant increase in the number of varieties of products within a category. There are difficulties in registration of trademarks, names that consist of five or fewer letters.

The sixth reason: effective communication of the organization with it's target market is difficult due to the saturation of advertising, consumer selectivity, ignoring them commercial communications.

In this situation, an arsenal of marketing tools impacting on the consumer is becoming more refined, innovative. In the marketing area with similar characteristics system of attitudes of consumers on the one hand, an internal reference point for consumers, and on the other-a "lighthouse", target for manufacturers and sellers.

\subsection{The Profiles of the Valuables of Consumers-Tatars and Russians}

To construct the profile of the valuables of consumers we used the technique LOV. The basis of the profile was based on the values that the respondents assigned the highest rank. Results of the study are tabulated below (Table 1). 
Table 1.The system of values of consumers Tatars ( $\%$ of respondents who put the value the highest rank)

\begin{tabular}{llll}
\hline Values & Total & Women & Men \\
\hline Self-fulfillment & 26.3 & 21.3 & 34.5 \\
Excitement & 3.3 & 3.2 & 3.4 \\
Sense of accomplishment & 12.5 & 16.0 & 6.9 \\
Self-respect & 9.2 & 7.4 & 12.1 \\
Sense of belonging & 8.55 & 9.6 & 6.9 \\
Being well respected & 12.5 & 10.6 & 15.5 \\
Security & 8.55 & 9.6 & 6.9 \\
Fun and enjoyment of life & 7.9 & 9.6 & 5.2 \\
Warm relationships with others & 11.2 & 12.8 & 8.6 \\
In total & 100 & 100 & 100 \\
\hline
\end{tabular}

On the basis of the ratings (from high to low rating) it is possible to construct the following value-profile of consumers-Tatars: self-fulfillment, a sense of accomplishment and being well respected; warm relationships with others, self-respect, a sense of belonging and security, fun and enjoyment of life, excitement. The largest group of consumers - those who put a high level of "self-fulfillment": $26.3 \%$. The smallest - those who put the needs of high rank "excitement": $3.3 \%$.

Comparative analysis of attitudes of men and women showed that there are some differences. For example, more than a one third of men and just over one fifth of women emphasized the greatest importance of the values of "self-fulfillment". Among men, the second largest group includes respondents who have a high rank "being well respected" (15.5\%), and the third-“self-respect" (12.1\%). The women's second group-those who put a high rank value "sense of accomplishment" (16\%) and the third-"warm relationships with others" (12.8\%).

The largest discrepancy in the evaluation of male and female values is such as self- fulfillment $(34.5 \%$ and $21.3 \%$, respectively), a sense of accomplishment (6.9\% of men and $16.0 \%$-women), being well respected (15.5\% of men and $10.6 \%$-women).

Table 2. The system of values of Russian consumers (\% of respondents who put the value of the highest rank)

\begin{tabular}{llll}
\hline Values & Total & Women & Men \\
\hline Self-fulfillment & 27.1 & 28.6 & 24.1 \\
Excitement & 3.5 & 4.5 & 1.7 \\
Sense of accomplishment & 15.3 & 12.5 & 20.7 \\
Self-respect & 14.1 & 14.3 & 13.8 \\
Sense of belonging & 8.2 & 7.1 & 10.3 \\
Being well respected & 6.5 & 8.0 & 3.5 \\
Security & 13.0 & 14.3 & 10.3 \\
Fun and enjoyment of life & 4.1 & 2.7 & 6.9 \\
Warm relationships with other & 8.2 & 8.0 & 8.6 \\
In total & 100 & 100 & 100 \\
\hline
\end{tabular}

Value-profile of Russian consumers (Table 2), constructed on the basis of the ratings (from high to low rating), as follows: self-fulfillment, a sense of accomplishment, self- respect, security, warm relationships with others and a sense of belonging, being well respected, fun and enjoyment of life, excitement.

Among the Russian respondents the largest consumer group includes those who put a high level of "self-fulfillment": $27.1 \%$. The smallest—those who put a high rank values "excitement": $3.5 \%$. Comparative analysis of attitudes of Russian respondents indicated the presence of gender specificity. Among men, the second 
largest group includes respondents who have a high level of "sense of accomplishment" (20.7\%), and the third-"self-respect" (13.8\%). The women's second group - those who put a high rank values "self-respect" $(14.3 \%)$ and "security" (14.3\%). The largest discrepancy in the evaluation of male and female values is such as "sense of accomplishment" (20.7\% and $12.5 \%$, respectively), self-fulfillment, security.

Structure of attitudes of Russian and Tatar women differ in almost all parameters. Among Russian respondents most rating values are following: self-fulfillment ( $28.6 \%$ vs. $21.3 \%$ Tatars), self-respect ( $14.3 \%$ vs. $7.4 \%$ Tatars), security $(14.3 \%$ vs. $9.6 \%$ Tatars), etc. For the Tatar women more rating values were such as a sense of accomplishment ( $16.0 \%$ vs. $12.5 \%$ for Russian women), warm relationships with others ( $12.8 \%$ vs. $8.0 \%)$; fun and enjoyment of life (9.6\% vs. $2.7 \%$ for Russians), etc.

Structure of attitudes of Russian and Tatar men also differ in almost all parameters. However, among Russian men, the most rating compared to Tatar men were the following values: a sense of accomplishment $(20.7 \%$ vs. $6.9 \%$, respectively), a sense of belonging $(10.3 \%$ vs. $6.9 \%)$, security $(10.3 \%$ vs. $6.9 \%)$. Rating values among the Tatar men were self-fulfillment (34.5\% of Tatars vs. $24.1 \%$-Russians), being well respected (15.5\% vs. $3.5 \%)$.

\subsection{Focuses of Consumer Behavior: Russians and Tatars}

Based on values such as self-fulfillment, excitement, a sense of accomplishment, self-respect consumers with a predominance of internal focus, with emphasis on internally oriented values are allocated. Consumers with a predominance of internal focus tend make independent decisions, control over their lives. Based on values such as a sense of belonging, being well respected, security, consumers identified priority of external focus. They are more inclined to harmonize their purchasing behavior with the majority of society. Interpersonal focus is determined by the highest ranking values such as fun and enjoyment of life, warm relationships with others (Table 3).

Table 3. Focuses of consumer behavior (\%)

\begin{tabular}{lll}
\hline Focuses & Russians & Tatars \\
\hline Internal & 60 & 51.3 \\
External & 27.7 & 29.6 \\
& & \\
Interpersonal & 12.3 & 19.1 \\
In total & 100 & 100 \\
\hline
\end{tabular}

It is obvious that among the Russians and Tatars majority of consumers has a predominance of values internal focus in the structure of attitudes. However, there are some differences: for the Russian respondents gap between of the internal focus and the rest focuses is stronger than for the Tatar respondents. At the same time the highest interpersonal focus is typical for Tatar women, it is $22.4 \%$, and the lowest-for Russian women-10.7 \%. Russian men don't want to harmonize their purchasing behavior with society. Priority of the external focus is observed for $24.2 \%$ of Russian men. Tatar women have maximum priority of external focus $-29.8 \%$.

We compared the ethnic and gender differences in the structure of values and obtained the following results. For groups of respondents, selecting the first two values (self-fulfillment and excitement), the differences in the approaches of men and women were higher than that of the Tatars and Russians. In the remaining seven values ethnic differences appeared more noticeable than gender. This indicates the predominance of the ethnic factor impact on the value orientations of consumers compared to gender.

\section{Discussions}

1) Ethnic model of consumer practices - image of consumers ethnically self-determined in specific economic, legal, social, ethnic and cultural, demographic conditions. This model is constructed based on numerous internal and external factors affecting the market behavior of the ethnos.

2) The results of the analysis of consumer practices of the two ethnic groups of the Republic of Tatarstan-Tatars and Russians - suggest a combination of two opposing processes: blurring of ethnic and cultural space and returning to the ethnic traditions.

3) Value-based approach for the study of the needs can be applied for the construction of ethnic consumer profile, which is one of the elements of ethnic model of consumer practices. 
4) According to our interrogations, focuses of the consumer behavior of Tatars and Russians considerably differ from each other, but also we were not able to identify the polar opposites in this sense.

5) As a result of our study revealed that ethnic differences exceed gender of most values studied.

\section{Conclusion}

The modeling of consumer behavior is one of popular area of economic anthropology. Constructing value profiles of Tatars and Russians of the Republic of Tatarstan - multiethnic and multicultural region of Russian Federation - is one of the elements of the model of consumer practices of these ethnic groups. Consumer practices are constantly under the influence of external and internal factors, and their systematic study is the task of further researches of authors. Comparative studies of consumer practices of other ethnic groups of Russia in the context of globalization also pose a serious scientific interest. Regular monitoring of the dynamics of the consumer practices of ethnic groups allows to monitor the socio-cultural and socio-economic processes in the interests of both the market subjects (organizations of industry, commerce, finance, transport, communications, advertising, tourism, entertainment and others) as well as various social groups. State and municipal government should play in the process leading role, in the interests of individual groups of consumers and society as a whole.

\section{Acknowledgments}

This article was prepared by authors with the financial support of the Russian Humanitarian Scientific Foundation (project number 12-01-00018a-"Ethno-cultural models of consumer practices: the case of the Republic of Tatarstan").

\section{References}

Aleshina, I. V. (2006). Consumer Behavior. Moscow: FAIR-PRESS.

Appadurai, A. (1986). Introduction: Commodities and the Politics of Value. In The Social Life of Things, Commodities in cultural Perspective (pp. 3-63). New York, NY: Cambridge University Press. http://dx.doi.org/10.1017/CBO9780511819582.003

Assael, H. (1993). Marketing: Principles \& Strategy. The Dryden Press. Harcourt Brace College Publishers.

Blackwell, R. D., Engel, J. F., \& Miniard, P. W. (2005). Consumer Behavior. South-Western College Pub: Cengage Learning

Ethnic composition of the population of the Republic of Tatarstan according to the census. (2010). Retrieved October 10, 2014, from http://tatstat.gks.ru/

Gabdrahmanova, G. F. (2010). Ethnic and cultural resources of economic development. Kazan: Kazan University

Ilyin, V. I. (2000). Consumer Behavior. Sankt-Peterburg: Piter.

Kahle, L. R. (1983). Social values and social change: Adaptation to life in America. Praeger Publishers.

Kotler, N., \& Kotler, P. (1999). Marketing Management: Analysis, Planning, Implementation and Control (9th ed.). Prentice Hall.

Kotler, P., \& Trias de Bes, F. (2003). Lateral Marketing: Lateral Marketing: New Techniques for Finding Breakthrough Ideas. John Wiley \& Sons, Inc.

Lambin, J-J. (2007). Market-Driven Management, Second Edition: Strategic and Operational Marketing. Palgrave Macmillan.

Lind de Montoya, M. (2009). Opening up new directions in economic anthropology. Economic Sociology, 4, 84-91.

List of Values. (2014). Retrieved October 10, 2014, from http://www.stevepavlina.com/articles/list-of-values.htm

Maslow, A. (1943). A Theory of Human Motivation. Psychological Review, 4, 370-396. http://dx.doi.org/10.1037/h0054346

Naumov, V. N. (2009). Models of consumer behavior in marketing systems. Sankt-Peterburg: Pub.SPbGUEF.

Rokeach, M. (1973). The Nature of Human Values. New York, NY: Free Press.

Rostovtseva, L. I. (2002). Consumer behavior and consumer culture. Moscow: Moscow University.

Rychkova, N. V., \& Rychkov, S. J. (2013). Ethnic models of consumer practices (for example the Republic of Tatarstan): Part I. Kazan: Kazan University.

Shvarts, Sh. (2009). Three approaches to measuring cultures. In Economic modernization and globalization (pp. 
277-281). Moscow, M: GU-VSE.

Shvarts, Sh., Butenko, T. P., Sedova D. S., \& Lipatova A. S. (2014). Refined theory of basic individual values: Application in Russia. Retrieved October 10, 2014, from http://www.hse.ru/data/2012/11/16/1248737841/Shvarts,\%20 Butenko,\%20, Sedova \%20 Lipatova -authors.pdf

\section{Copyrights}

Copyright for this article is retained by the author(s), with first publication rights granted to the journal. This is an open-access article distributed under the terms and conditions of the Creative Commons Attribution license (http://creativecommons.org/licenses/by/3.0/). 